\title{
Significance of Irisin (FNDC5) Expression in Colorectal Cancer
}

\author{
SLAWOMIR WOZNIAK ${ }^{1}$, KATARZYNA NOWINSKA $^{2}$, MARIUSZ CHABOWSKI ${ }^{3,4}$ and PIOTR DZIEGIEL ${ }^{2}$ \\ ${ }^{1}$ Division of Anatomy, Department of Human Morphology and Embryology, \\ Wroclaw Medical University, Wroclaw, Poland; \\ ${ }^{2}$ Division of Histology and Embryology, Department of Human Morphology and Embryology, \\ Wroclaw Medical University, Wroclaw, Poland; \\ ${ }^{3} 4^{\text {th }}$ Military Surgical Clinic in Wroclaw, Wroclaw, Poland; \\ ${ }^{4}$ Division of Anesthesiologic and Surgical Nursing, Department of Nursing and Obstetrics, \\ Faculty of Health Science, Wroclaw Medical University, Wroclaw, Poland
}

\begin{abstract}
Background/Aim: The role of irisin, the extracellular part of fibronectin type III domain containing 5 (FNDC5), in colorectal cancer $(C R C)$ is unclear. The aim of this study was to investigate immunohistochemical (IHC) expression level of irisin and correlations with clinicopathological factors in patients with CRC. Materials and Methods: We collected 222 archived CRC samples and 26 control samples from autopsies conducted at the Department of Forensic Medicine. They were used to perform IHC reactions detecting irisin, Ki-67, minichromosome maintenance protein complex component 3 (MCM3), and urine diphosphate-galactose ceramide galactosyltransferase (UGT3) expression. The correlations with $\mathrm{Ki}-67, \mathrm{MCM} 3$, and UGT3 were analyzed. Irisin expression was also evaluated in cancer cell lines by immunofluorescence reaction and western blot. Results: Irisin expression was higher in cancer cells compared to the control tissues $(p<0.0001)$. Irisin expression was significantly higher in stage I than in stage III ( $p=0.013)$ and IV CRC ( $p=0.05)$. Conclusion: The correlation between higher expression of irisin and cancer stages indicates its potential usefulness as a marker in CRC.
\end{abstract}

Currently, colorectal cancer (CRC) is the world's fourth most deadly cancer, causing almost 900,000 deaths annually (1). It is the second most commonly diagnosed cancer annually and the second most common cause of death among all types of cancer in Europe - 500,000 new cases and 243,000 deaths were reported in 2018 (2). The morbidity and mortality in the

This article is freely accessible online.

Correspondence to: Katarzyna Nowinska, Department of Human Morphology and Embryology, Division of Histology and Embryology, Wroclaw Medical University, Chalubinskiego st. 6a, 50-368 Wroclaw, Poland. Tel: +48 717841354, e-mail: katarzyna.nowinska@umw.edu.pl

Key Words: FNDC5, irisin, colorectal cancer, Ki-67.
USA are similar - approximately 135,000 new cases and more than 50,000 deaths in 2017 (3). In Poland, between 1980 and 2013, there was a 4.2-fold increase in CRC morbidity in men (from 2,288 to 9,548) and a 3.2-fold increase in women (from 2,432 to 7,902 ), with $75 \%$ of new cases being diagnosed in patients over 60 years of age in both sexes. In 2017, CRC was diagnosed in 10,905 patients from the Polish population (5,073 women and 5,832 men) (4). The etiopathology of this cancer is multifactorial, and the main causes, which are well known, include an aging population, obesity (due to dietary habits), lack of physical exercise, smoking, and immune system pathology $(1,5,6)$. The response of the immune system to pathological signs may lead to carcinogenesis $(7,8)$.

The extracellular peptide known as irisin is released from skeletal muscle by an unknown protease acting on fibronectin type III domain containing 5 (FNDC5), and plays an essential role in regulating energy homeostasis. It was detected for the first time by Boström et al. in 2012 (9). Apart from converting different adipose tissues, it is involved in other metabolic activities, e.g., inflammatory processes and aging (10). Moreover, increased irisin expression was reported in some digestive tract malignancies (e.g., hepatocellular, colon, esophageal, and gastric cancer) (11-13). Its role in pancreatic cancer is unclear $(14,15)$. Therefore, we were interested in understanding the role of associated factors (including irisin) in the progression of CRC.

Our study is the continuation of our research on irisin expression in lung cancer (16). We observed increased irisin expression in cancer cells and stromal cells of lung cancer. Higher irisin expression in stromal cells of lung cancer was observed in patients with shorter overall survival. Moreover, irisin expression correlated with $\mathrm{Ki}-67$ expression in stromal cells of lung cancer. Therefore, we investigated irisin expression in CRC. The Ki-67 antigen is routinely used in the diagnostic process to check the proliferative ability of different cancer types. Minichromosome maintenance protein complex component 3 (MCM3) is also a proliferation 
marker. This protein is a part of the MCM complex, which participates in replication. Its increased expression has been observed in various cancer types $(17,18)$.

Additionally, urine diphosphate-galactose ceramide galactosyltransferase (UGT8) influences sulfatide biosynthesis and is also related to cell proliferation. Increased sulfatide activates integrin $\alpha \mathrm{V} \beta 5$-mediated signaling, which contributes to breast cancer progression (19). Research has also demonstrated that $\alpha \mathrm{V}$ integrins are receptors for irisin in osteocytes (20). Therefore, we investigated irisin expression in CRC and its correlation with the markers Ki-67, MCM3, and UGT8. Furthermore, the aim of this study was to evaluate irisin expression in association with clinicopathological parameters in CRC.

\section{Materials and Methods}

Patient characteristics. This was a retrospective study conducted on 222 archived paraffin blocks from patients with CRC (women $n=90$; men $n=132$ ) (Table I). The specimens were collected between 2012 and 2016 during surgical removal of tumor. The surgical procedures were conducted at the Wroclaw Military Hospital. Patients whose specimens were analyzed had a sedentary lifestyle. They had not undergone chemo- or radiotherapy before surgery. Patients were excluded from the study if they were diagnosed with any other cancer. All the patients in the analyzed group were diagnosed with CRC. The histopathological evaluation was made in accordance with the World Health Organization criteria, and the pathological staging was standardized according to the eighth TNM edition (21).

The control group (26 specimens) included samples from autopsies conducted at the Department of Forensic Medicine in Wroclaw. Tissues were collected from every segment of the colon. Only patients with sudden death were included. The exclusion criteria were as follows: Other neoplasms, gastrointestinal tract surgery, intestinal inflammation, or intoxication. Samples of poor quality were excluded from further analysis. The project was approved by the Bioethics Committee at Wroclaw Medical University (no. 604/2018)

Cell line and culture conditions. Three intestinal cancer cell lines were used in in vitro studies, namely CaCo-2, LoVo and HT-29, and the normal intestinal cell line CCD-18Co. Appropriate culture media were used to culture the cell lines. CaCo- 2 cells were grown in minimum essential medium (Lonza, Switzerland, Basel), LoVo in F-12K medium (American Type Culture Collection, Manassas, VA, USA), HT-29 in McCoy's 5A medium (Merck KGaA, Darmstadt, Germany), and CCD-18Co in Eagle's minimum essential medium (Lonza). All culture media were supplemented with $10 \%$ fetal bovine serum (Merck KGaA) except for the CaCo-2 cell culture medium to which $20 \%$ fetal bovine serum (Merck KGaA) and $1 \%$ non-essential amino acids (Merck KGaA) were added. All culture media were also supplemented with $1 \%$ penicillin/streptomycin (Merck KGaA). Cell cultures were maintained in a humid atmosphere at $37^{\circ} \mathrm{C}$ with $5 \% \mathrm{CO}_{2}$. Cells were trypsinized with $0.25 \%$ trypsin (Merck KGaA).

Tissue microarray (TMA) preparation. The material for the study consisted of 222 archived paraffin-embedded samples of colon
Table I. Clinicopathological characteristics of patients $(n=222)$ related to irisin expression in colorectal cancer cells.

\begin{tabular}{|c|c|c|c|c|}
\hline \multirow[b]{2}{*}{$\begin{array}{l}\text { Clinicopathological } \\
\text { parameter }\end{array}$} & \multirow[b]{2}{*}{$\begin{array}{l}\text { Frequency, } \\
\text { n }(\%)\end{array}$} & \multicolumn{3}{|c|}{ Irisin expression in CRC cells } \\
\hline & & $\begin{array}{l}\text { Low } \\
(<6)\end{array}$ & $\begin{array}{r}\text { High } \\
(\geq 6)\end{array}$ & $p$-Value* \\
\hline Age & & & & 0.6268 \\
\hline$\leq 60$ Years & $51(22.96)$ & 21 & 30 & \\
\hline$>60$ Years & $171(77.04)$ & 77 & 94 & \\
\hline Gender & & & & 0.3680 \\
\hline Male & $132(59.47)$ & 55 & 77 & \\
\hline Female & $90(40.53)$ & 43 & 47 & \\
\hline Tumor size & & & & 0.5439 \\
\hline $\mathrm{T} 1$ & $1(0.89)$ & 0 & 1 & \\
\hline $\mathrm{T} 2$ & $28(24.56)$ & 7 & 21 & \\
\hline $\mathrm{T} 3$ & $79(69.29)$ & 27 & 52 & \\
\hline $\mathrm{T} 4$ & $6(5.26)$ & 3 & 3 & \\
\hline Lymph node status & & & & 0.1776 \\
\hline NO & $70(61.40)$ & 26 & 44 & \\
\hline N1-N3 & $44(38.60)$ & 11 & 33 & \\
\hline Metastasis & & & & 0.1283 \\
\hline M0 & $95(83.34)$ & 28 & 67 & \\
\hline M1 & $19(16.66)$ & 9 & 10 & \\
\hline Stage & & & & 0.3340 \\
\hline I & $22(19.30)$ & 5 & 17 & \\
\hline II & $40(35.08)$ & 14 & 26 & \\
\hline III & 33 (28.94) & 9 & 24 & \\
\hline IV & $19(16.66)$ & 9 & 10 & \\
\hline Grade of malignancy & & & & 0.2844 \\
\hline 1 & $44(19.81)$ & 16 & 28 & \\
\hline 2 & $156(70.27)$ & 68 & 88 & \\
\hline 3 & $19(8.56)$ & 11 & 8 & \\
\hline Ki67 score index & & & & 0.0352 \\
\hline $1-2$ & $107(48.27)$ & 51 & 56 & \\
\hline $3-4$ & $115(51.73)$ & 71 & 44 & \\
\hline MCM3 score index & & & & 0.0189 \\
\hline $1-2$ & $84(37.93)$ & 59 & 25 & \\
\hline $3-4$ & $138(62.07)$ & 75 & 63 & \\
\hline UGT8 score index & & & & 0.1045 \\
\hline $1-6$ & $128(57.5)$ & 50 & 78 & \\
\hline $7-12$ & $94(42.5)$ & 47 & 47 & \\
\hline
\end{tabular}

MCM3: Minichromosome maintenance protein complex component 3; UGT8: urine diphosphate-galactose ceramide galactosyltransferase. *By chi-squared test. Statistically significant $p$-values are shown in bold.

adenocarcinoma. Sections 7- $\mu$ m-thick were stained with hematoxylin and eosin and later scanned using a histology scanner Pannoramic MIDI (3DHistech, Budapest, Hungary) under 20× magnification to create virtual slides. Scans were examined by two independent pathologists, and representative spots were selected to create microarrays (three spots from each block, $1.5 \mathrm{~mm}$ diameter each). TMAs were created using TMA Grand Master automatic system (3DHistech).

Immunohistochemistry (IHC) reactions. IHC was performed on 4$\mu$ m-thick sections obtained from the TMA blocks using a Link48 Autostainer (Dako, Glostrup, Denmark). To deparaffinize, rehydrate 
and unmask the epitope, the slides were boiled in EnVision FLEX Target Retrieval Solution $\left(97^{\circ} \mathrm{C}, 20 \mathrm{~min} ; \mathrm{pH}\right.$ 9) in PT-Link. The activity of endogenous peroxidase was blocked by 5-min incubation with EnVision FLEX Peroxidase-Blocking Reagent (Dako). Next, primary rabbit polyclonal anti- irisin/FNDC5 antibody (NBP214024; Novus Biologicals, Littleton, CO, USA) was applied at 1:300 for $1 \mathrm{~h}$. Next, the slides were incubated with EnVision FLEX/horseradish peroxidase (HRP) for $20 \mathrm{~min}$. Finally, a substrate for HRP (3,3'-diaminobenzidine) was added for 10-min incubation. All sections were counterstained with EnVision FLEX Hematoxylin (Dako) for $5 \mathrm{~min}$. After dehydration in graded ethanol concentrations $(70 \%, 96 \%, 99.8 \%)$ and xylene, the slides were sealed with coverslips in Dako Mounting Medium (Dako). After IHC, TMAs were analyzed to evaluate irisin expression using a BX41 Optical Microscope (Olympus Hamburg, Germany) at $\times 200$ magnification. The semiquantitative immunoreactive score by Remmele and Stegner (22) was used for the assessment of cytoplasmic irisin and UGT8 reaction. The final result was the product of the scores obtained by the estimation of the intensity of the color reaction (i.e., 1 point for weak, 2 point for moderate, 3 point for strong reaction) and the percentage of positively stained cancer cells ( 0 points: no expression, 1 point: $1-10 \%, 2$ points: $11-$ $50 \%, 3$ points: $51-80 \%, 4$ points: $>80 \%$ ) (22). Nuclear IHC reaction of Ki-67 and MCM3 were determined with the use of the five-point evaluation scale (0-no expression, 1 point $-1 \%-10 \%, 2$ points$11 \%-25 \%, 3$ points $-26 \%-50 \%, 4$ points $>50 \%$ ). The assessment was performed by two independent pathologists. Discrepancies were re-evaluated until concensus.

Immunofluorescence. Caco-2, Lovo, HT-29, and CCD-18Co cell lines were set up at $2 \times 10^{4}$ cells per well in Millicell EZ 8-well glass slides (Merck $\mathrm{KGa}$ ) in appropriate medium overnight.

The cells were then fixed with $4 \%$ paraformaldehyde for $12 \mathrm{~min}$ at room temperature and permeabilized using $0.2 \%$ Triton $\mathrm{X}-100$ for $10 \mathrm{~min}$. Non-specific binding was blocked using $3 \%$ bovine serum albumin (BSA) in $0.1 \%$ phosphate-buffered saline buffer $(1 \mathrm{~h}$ at room temperature). The cells were incubated overnight at $4{ }^{\circ} \mathrm{C}$ with primary anti-Irisin/FNDC5 (dilution 1:200; NBP2-14024; Novus Biologicals). Subsequently, secondary anti-rabbit Alexa Fluor 568 was applied at 1:2,000 (ab175470; Abcam, Cambridge, UK), for 1 $\mathrm{h}$ at room temperature. Negative controls were performed with $1 \%$ BSA in phosphate-buffered saline instead of the specific antibody. The preparations were mounted in the ProLong Gold Antifade Mountant with 4',6-diamidino-2-phenylindole (Thermo Fisher Scientific, Waltham, MA, USA). A Fluoview FV3000 (Olympus) confocal laser scanning microscope coupled with CellSense software (Olympus) was used for evaluating fluorescence at a magnification of $\times 600$.

Protein isolation and western blot. The whole-cell protein lysates from CCD-18Co, HT-29, CaCo-2, and LoVo cell lines were extracted using CelLytic ${ }^{\mathrm{TM}}$ MT Cell Lysis Reagent (Sigma-Aldrich, Saint Louis, MO, USA) with the addition of Halt ${ }^{\mathrm{TM}}$ Protease Inhibitor Cocktail (Thermo Fisher Scientific, Waltham, MA, USA) and $0.2 \mathrm{mM}$ PMSF Protease Inhibitor (Sigma-Aldrich). Protein concentrations were quantified with a Pierce BCA Protein Assay Kit (Thermo Fisher Scientific) and a NanoDrop ${ }^{\mathrm{TM}} 1000$ (Thermo Fisher Scientific) spectrophotometer. Equal amounts of total protein $(30 \mu \mathrm{g})$ were mixed with the Laemmli sample buffer (23) and resolved on $10 \%$ acrylamide gel by sodium dodecyl sulphate-polyacrylamide gel electrophoresis. After electrophoresis, the samples were transferred to Immobilon-P polyvinylidene difluoride membranes (Merck Darmstadt, Germany) in the XCell SureLock ${ }^{\mathrm{TM}}$ Mini-Cell Electrophoresis System (Thermo Fisher Scientific). Next, the membranes were blocked in $4 \%$ BSA (Merck KGaA) solution in TBST buffer (0.2 M Tris; $1.5 \mathrm{M} \mathrm{NaCl} ; 0.1 \%$ Tween-20). After blocking, the membranes were incubated overnight at $4^{\circ} \mathrm{C}$ with primary polyclonal rabbit antibody to irisin/FNDC5 (NBP2-14024; Novus Biologicals, Centennial, CO, USA) diluted at 1:200. The membranes were also incubated for $1 \mathrm{~h}$ at room temperature with secondary HRP-conjugated donkey anti-rabbit antibody (711-035152; Jackson ImmunoResearch, West Grove, PA, USA) diluted at 1:3,000. Finally, the membranes were rinsed and treated with Luminata Classico (Merck KGaA) chemiluminescent substrate. The data were collected using the ChemiDoc Imaging System (Bio-Rad, Hercules, CA, USA). $\beta$-Tubulin, detected with primary rabbit antihuman $\beta$-tubulin (ab6046; Abcam) diluted at 1:1,000, and the secondary HRP-conjugated donkey anti-rabbit antibody (711-035152; Jackson ImmunoResearch) diluted at 1:3,000, was used as an internal control to normalize the amounts of irisin/FNDC5. The densitometric analysis of the results was performed using Image Lab software suite (Bio-Rad). The experiment was performed in triplicate.

Statistical analysis. The associations between the IHC expression of irisin/FNDC5 and clinical parameters were analyzed statistically with GraphPad Prism 5.0 (La Jolla, CA, USA). The data distribution was evaluated with the Kolmogorov-Smirnov test. All the quantitative variables were described as medians and ranges. The Mann-Whitney $U$-test, the Kruskal-Wallis test, and the $\mathrm{Chi}^{2}$ test were used to compare the analyzed groups. Spearman's rank correlation was used to evaluate the association between the expression of the Ki-67 antigen, MCM3 and UGT8 and that of irisin in cancer cells. Kaplan-Meier analysis and the log-rank test were used to verify the relationship between the intensity of irisin expression and patient overall (OS) and event-free (EFS) survival. The results were considered statistically significant when $p<0.05$.

\section{Results}

IHC evaluation of irisin expression levels in CRC TMAs. We found weak or no expression of irisin in normal colorectal cells in 26 cases (Figure 1A); strong irisin expression was present only in goblet cells (Figure 1B). In CRC cells, the IHC reaction showed irisin in the cytoplasm (Figure 1C-E). In $\mathrm{CRC}$, we also observed the presence of irisin in the apical part of cells and the extracellular space (Figure 1D). The mean irisin expression level in CRC cells was significantly higher than in normal colorectal cells $[6.51 \pm 2.46$ (SD) vs. $4.86 \pm 1.48$ (SD), respectively; $p=0.0016$, Mann-Whitney $U$-test].

Associations between irisin expression in CRC cells and clinicopathological parameters. We compared the mean values of irisin expression and their relationship with the clinicopathological parameters (Table I and Table II). We observed changes in irisin levels according to tumor size, grade of malignancy, lymph node status, and distant metastasis. Irisin levels decreased with higher T-status. 

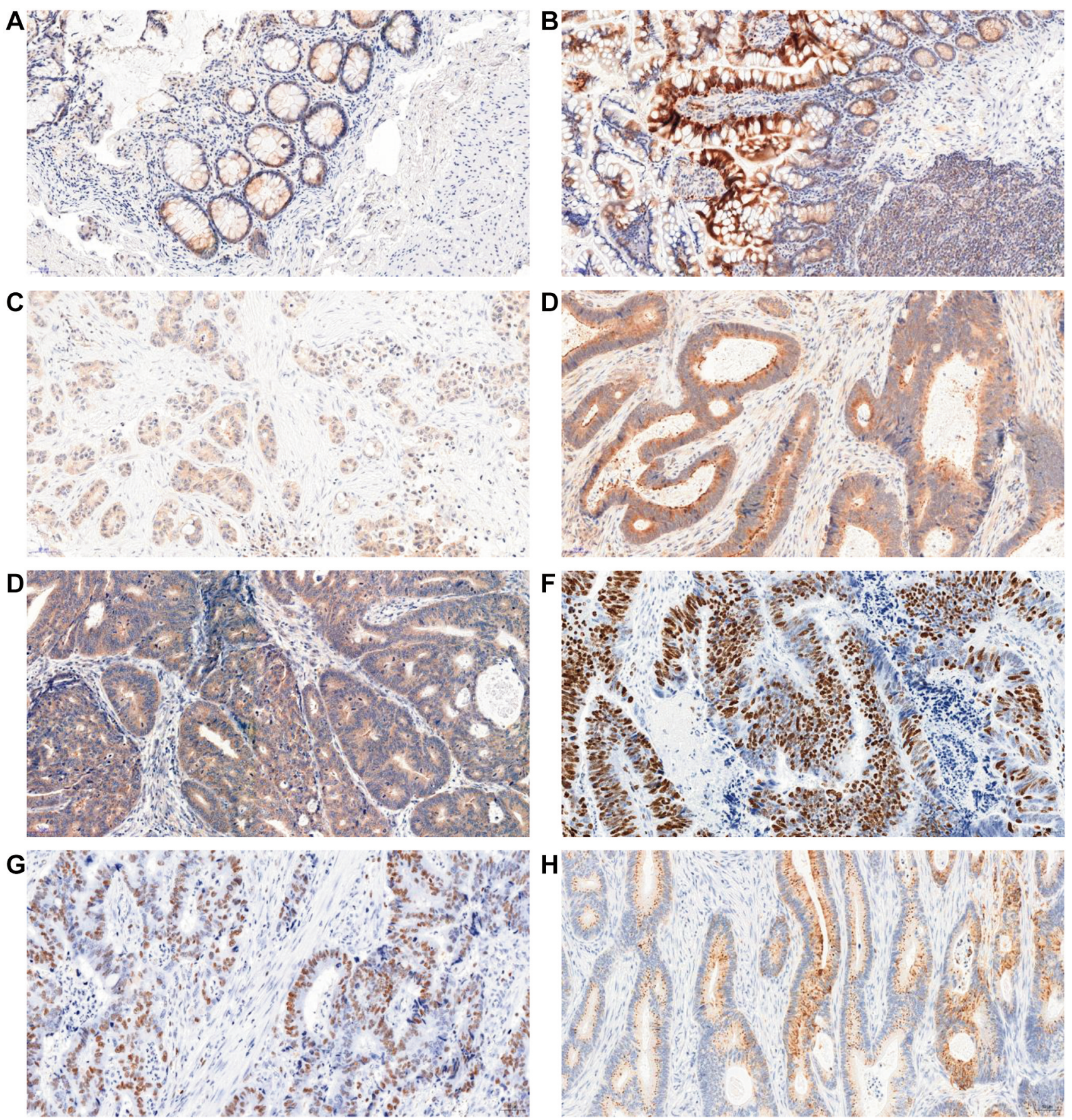

Figure 1. Immunohistochemical reactions (brown color) for irisin, Ki-67, minichromosome maintenance protein complex component 3 (MCM3) and urine diphosphate-galactose ceramide galactosyltransferase (UGT8) expression in colorectal cancer (CRC). Irisin cytoplasm expression in healthy colorectal tissue (A: no expression, B: expression in goblet cells) and in different grades of malignancy of CRC (C: grade 1, D: grade 2, E: grade 3) as evidenced by brown-stained cytoplasm. CRC tissue was also positive for expression of Ki-67 (F), MCM3 (G) and UGT8 (H); magnification, $\times 200$.

Differences between T1-T2 and T3-T4 were of borderline significance (Mann-Whitney $U$-test, $p=0.052$ ). The differences in irisin expression levels between groups of patients according to the $\mathrm{pN}$ or $\mathrm{pM}$ status were not statistically significant. We analyzed irisin expression in different CRC stages and observed significant differences between stages I and III (Mann-Whitney $U$-test, $p=0.01$ ) and between stages I and IV (Mann-Whitney $U$-test, $p=0.05$ ). 
Table II. Associations of irisin expression level with clinicopathological characteristics in patients with colorectal cancer.

\begin{tabular}{lcccc}
\hline Parameter & Subgroup & Mean value \pm SD & Comparison & $p$-Value* \\
\hline Lymph & N0 & $6.046 \pm 2.23$ & N0 vs. N1-N3 & 0.346 \\
nodes & N1-N3 & $5.830 \pm 2.07$ & & \\
Grade of & 1 & $6.206 \pm 2.53$ & 1 vs. 2 & 0.6345 \\
malignancy & 2 & $5.964 \pm 2.03$ & 1 vs. 3 & 0.3020 \\
& 3 & $5.438 \pm 2.44$ & 2 vs. 3 & 0.2416 \\
Tumor size & T1 & $8.00 \pm 0.0$ & T1-T2 $v s$. T3-T4 & 0.052 \\
& T2 & $7.49 \pm 2.24$ & T2 vs. T3 & 0.085 \\
& T3 & $6.23 \pm 2.54$ & T2 vs. T4 & 0.163 \\
& T4 & $5.93 \pm 1.90$ & T3 vs. T4 & 0.652 \\
Stage & I & $6.75 \pm 2.0$ & I vs. II & 0.077 \\
& II & $5.82 \pm 2.2$ & I vs. III & $\mathbf{0 . 0 1 3}$ \\
& III & $5.73 \pm 2.2$ & I vs. IV & 0.050 \\
& IV & $5.67 \pm 1.6$ & II $v s$. III & 0.438 \\
& & & II $v s$. IV & 0.618 \\
Metastasi & M0 & $5.98 \pm 2.21$ & III $v s$. IV & 0.981 \\
& M1 & $5.83 \pm 1.73$ & & 0.796
\end{tabular}

CRC: Colorectal cancer Statistically significant $p$-values are shown in bold. *Mann-Whitney $U$-test.

Associations between the expression of irisin and OS and $E F S$. We did not observe any differences in OS according to irisin expression in cancer cells in patients with CRC (logrank Mantel-Cox test; $p=0.46$ ) (Figure 2A). However, longer EFS was observed in patients with higher irisin expression (Figure 2B). This relationship was close to the statistical significance (log-rank Mantel-Cox test; $p=0.09$ ).

The results of the univariate and multivariate analyses are given in Table III. The multivariate analysis showed that a high grade of malignancy was related to shorter OS. Additionally, advanced $\mathrm{pT}$ and $\mathrm{pN}$ status and the stage of $\mathrm{CRC}$ were related to shorter OS.

Associations between the proliferation of cancer cells and irisin expression. We investigated the relationship between irisin levels and CRC cell proliferation. For this purpose, we compared the level of irisin with the proliferation markers such as the Ki-67 antigen, UGT8, and the MCM3 protein. Irisin expression in CRC cells weakly positively correlated with the expression of the Ki-67 antigen ( $\mathrm{r}=0.20, p=0.0395)$. Moreover, we observed a weakly positive correlation between irisin and MCM3 expression ( $\mathrm{r}=0.26, p=0.0091)$ and a medium positive correlation with UGT- $8 \quad(\mathrm{r}=0.34$, $p=0.0005$ ). Figure 3 shows plots of correlations with the markers of proliferation.

Irisin expression in CRC cell lines. We analyzed irisin expression of the normal colon cell line (CCD-18Co) compared to cancer cell lines (LoVo, HT29 and CaCo-2) by western blot and immunofluorescence reaction. The comparison of irisin levels is given in Figure 4. We observed higher expression of irisin in cancer cells compared to CCD18Co cells. The highest irisin level was found in LoVo cells, which are cells derived from a metastatic site.

\section{Discussion}

We performed our study on a large group of 222 patients to investigate irisin expression in CRC tissue specimens in association with different clinical parameters describing CRC. We also correlated the irisin expression by IHC with Ki-67, MCM3, and UGT8 in CRC. Additionally, we used an in vitro model and analyzed the differences in immunofluorescence between normal colon cells (CCD-18Co) and selected colon cancer lines (CaCo-2, LoVo and HT-29). Increased irisin concentration is responsible for a decrease in adenosine triphosphate (ATP) production. However, increased heat production is observed (24). We decided to investigate this molecule due to its importance - an increase in local heat can kill cancer cells by coagulating their proteins and destroys their small blood vessels (25).

Aydin et al. found that irisin was significantly increased in colon cancer cells (26). They suggested two explanations for this finding. Firstly, that it might be related to adaptation to changes in cell conditions (adaptation to inhibit ATP generation). Secondly, an increased irisin level raises the conversion of white adipose tissue to brown adipose tissue, which leads to the release of more heat through mitochondria that contain uncoupling protein 1 (the molecule that controls adaptive thermogenesis by the release of heat) rather than $\operatorname{ATP}(9,26,27)$.

We confirmed the above finding, obtained on tissues by IHC method, using immunofluorescence reaction in the selected colon cancer cells lines (CaCo, LoVo and HT29) compared to normal colon cells. Additionally, we found higher expression of irisin by immunofluorescence in CRC cell lines. Irisin is useful to differentiate between stage I (initial colon cancer) and more advanced stages of CRC. The levels of many molecules are increased in tumors. We revealed statistically significant correlations of irisin with Ki67, MCM3, and UGT3.

According to Shi et al., irisin stimulated cell proliferation, migration, and invasion of hepatocellular carcinoma. Furthermore, it reduced the cytotoxicity of doxorubicin in HepG2 cells, which suggests that an increased expression of irisin might have a protective role in liver cancer (13). These findings are not in line with those revealed by Aydin et al. (26), who did not report increased irisin levels in liver cancer (28). Zhu et al. showed that a reduced serum irisin level was detected in patients with CRC. Their research suggested irisin might be a new important diagnostic indicator for CRC (29). Zhang et al. found that irisin inhibited cell 
A

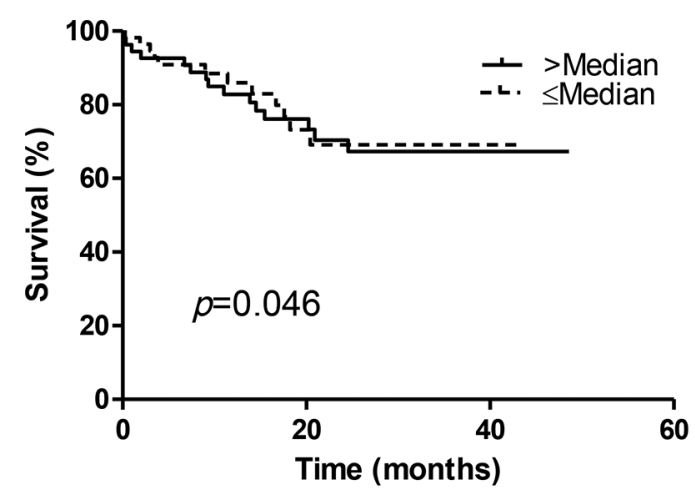

B

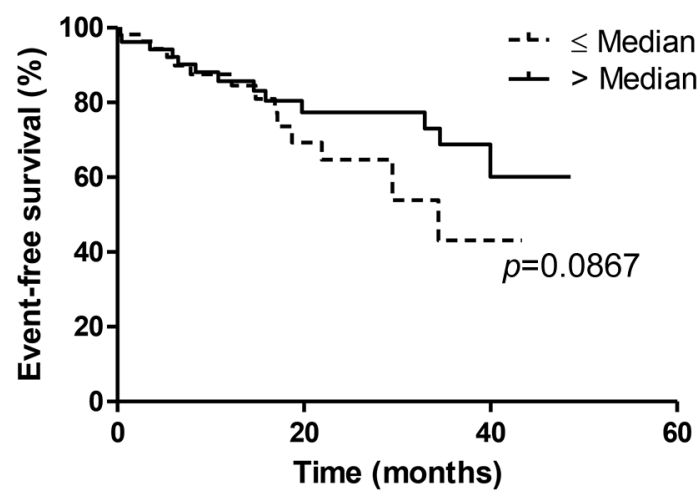

Figure 2. Kaplan-Meier survival curves presenting the prognostic impact of irisin expression levels detected by immunohistochemistry in cancer cells of patients with colorectal cancer on overall survival (A) and event-free survival (B). Patient groups were compared according to the median value of the immunohistochemical expression of irisin in colorectal cancer cells.

Table III. Univariate and multivariate Cox proportional hazards analyses in patients with colorectal cancer.

\begin{tabular}{|c|c|c|c|c|c|}
\hline \multirow[b]{2}{*}{ Parameter } & \multirow[b]{2}{*}{ Subgroup comparison } & \multicolumn{2}{|c|}{ Univariate analysis } & \multicolumn{2}{|c|}{ Multivariate analysis } \\
\hline & & HR $(95 \% \mathrm{CI})$ & $p$-Value & HR $(95 \% \mathrm{CI})$ & $p$-Value \\
\hline Age & $\leq 60 \mathrm{vs} .>60$ Years & $0.46(0.17-1.16)$ & 0.1050 & & \\
\hline Gender & Male vs. female & $0.98(0.46-2.03)$ & 0.9548 & & \\
\hline $\mathrm{pT}$ & $1-2$ vs. 3-4 & $2.58(1.17-5.73)$ & 0.0192 & $2.00(0.87-4.63)$ & 0.2016 \\
\hline $\mathrm{pN}$ & No vs. N+ & $1.93(0.90-4.10)$ & 0.0891 & & \\
\hline Grade & 1 vs. $2-3$ & $3.07(1.37-6.87)$ & 0.0062 & $4.86(1.14-20.70)$ & 0.0320 \\
\hline Stage & I-II $v s$. III-IV & $2.92(1.40-6.12)$ & 0.0043 & $2.28(0.63-8.06)$ & 0.1040 \\
\hline Irisin & $<25 \%$ vs. $\geq 25 \%$ & $1.41(0.61-3.32)$ & 0.4570 & & \\
\hline Ki-67 & $<25 \%$ vs. $\geq 25 \%$ & $0.97(0.51-1.85)$ & 0.9626 & & \\
\hline MCM3 & $<25 \%$ vs. $\geq 25 \%$ & $0.91(0.47-1.81)$ & 0.8158 & & \\
\hline
\end{tabular}

CI: Confidence interval; HR: hazard ratio; MCM3: minichromosome maintenance protein complex component 3. Statistically significant $p$-values are shown in bold.

proliferation, induced apoptosis, and reduced the migration and invasion of pancreatic cancer cells (15). These findings were the basis for our study on the role of irisin in CRC. Liu et al. showed that irisin suppressed the migration and invasion of selected pancreatic cancer cell lines (14). Moon et al. found that irisin had no effect on cell proliferation, adhesion, or malignant potential of obesity-related cancer cell lines (12).

In our opinion, the IHC analysis of irisin expression of cancer tissues offers considerable advantages over serumbased techniques. This protein is mostly produced in the muscles after exercise, and various tissues have different irisin concentrations. The serum level of this peptide shows fluctuation, which is related to discrepancies when the serum irisin level is correlated with clinical cancer parameters. We are of the opinion that irisin is a useful protein that can be used in further analysis. Irisin has been found in different cells (e.g., in muscles, pancreas, liver, brain, adipose tissue). It plays a role in regulating fat metabolism but is not related to specific cell physiology. Therefore, this protein may be responsible for energy balance of all cancer cells, thereby releasing the additional local heat.

We can support the findings for CRC clinical staging. We observed no correlation between IHC irisin expression and cancer cell malignancy or a clinical stage.

Altay et al. observed increased expression of FNDC5 in adipose tissue in mice with induced gastric cancer, but no expression in the gastric cancer group (30). We revealed the increased expression of irisin in CRC cells, which is not in line with the findings of the above authors.

We speculate that irisin may be responsible for thermal conditions inside CRC cells, thus leading to the progression of weight loss in cachexia. If so, further analysis is warranted to improve the treatment of cancer cachexia. This process is 
A

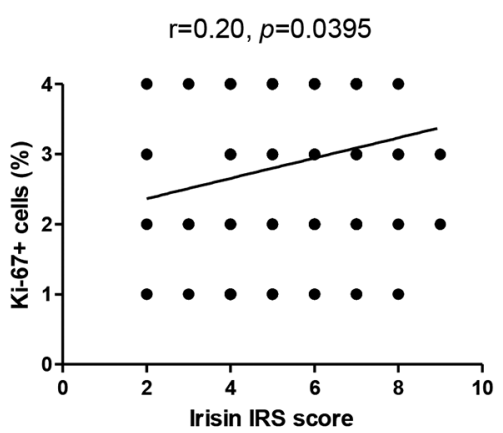

B

$r=0.26, p=0.0091$

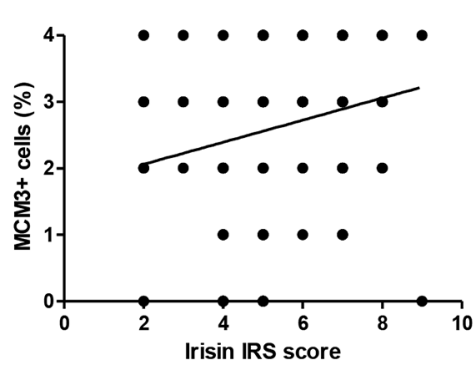

C

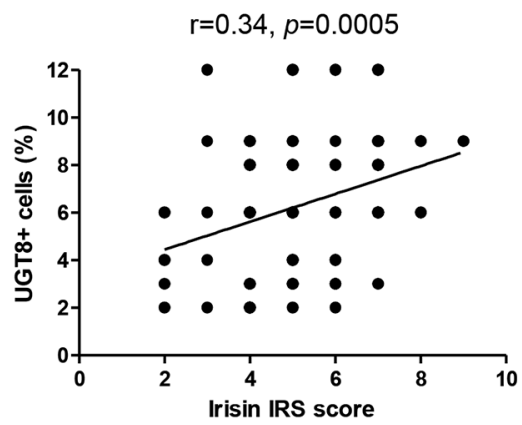

Figure 3. Correlations between irisin expression level and proliferation markers Ki-67 (A), minichromosome maintenance protein complex component $3(M C M 3)(B)$ and urine diphosphate-galactose ceramide galactosyltransferase (UGT8) (C) in colorectal cancer cells from patients. IRS: Immunoreactive score.
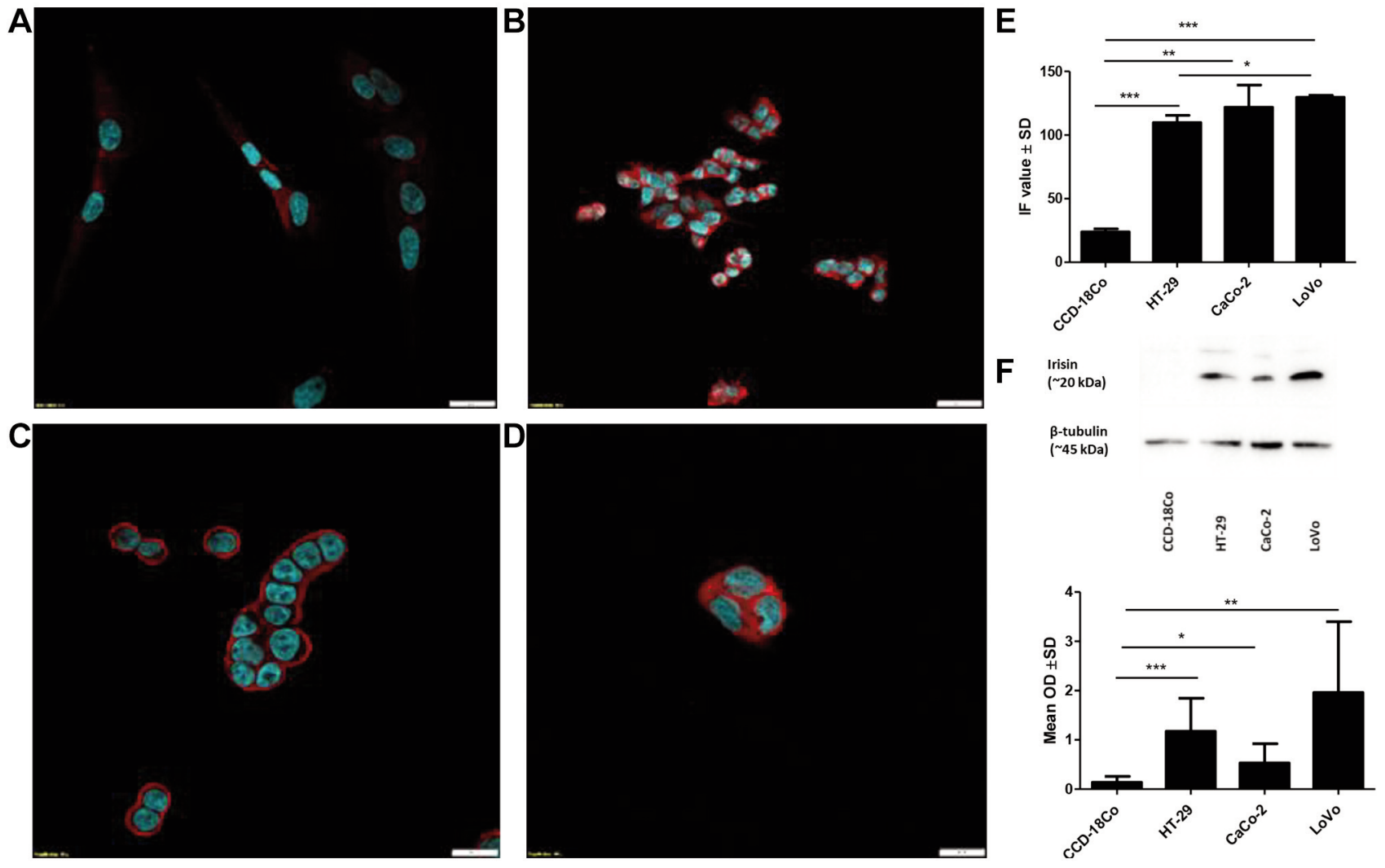

Figure 4. Comparison of irisin expression levels detected by the immunofluorescence (IF) method in normal colon CCD-18Co cells (A) and in different colorectal cancer cell lines (B: HT-29; C: CaCo-2; D: LoVo). Bars=20 $\mu \mathrm{m}$. The level of irisin expression was quantified by IF value (E) and western-blot densitometry $(F)$ in normal and cancer cells. Significantly different at $* p \leq 0.05, * * p \leq 0.005$ and $* * * p \leq 0.001$.

a multifactorial disease and can be found in $50-80 \%$ of patients with cancer (31). We speculate that the change in irisin production is observed during cancer progression, and is reflected by the differences in its level when stage $\mathrm{I}$ is compared to stage III or IV.
We speculate that different results of intracellular irisin levels can mirror the differences in the number or functions of irisin in different types of gastrointestinal cancer, and hence reflects the different results in gastric, liver, and colorectal cancer. There is a possibility that the situation in 
the gastrointestinal tract is similar to that of adipose tissue, in which the level of irisin expression is different in brown, white and beige tissues. Therefore, the final results in various types of cancer are also divergent. However, the data from our study may be useful for understanding the role of this peptide in CRC progression.

\section{Conflicts of Interest}

The Authors declare no conflicts of interest.

\section{Authors' Contributions}

$\mathrm{KN}$ : methodology, formal analysis and writing; SW: investigation, resources formal analysis, validation and writing; MC: data curation; PD: review and editing.

\section{Acknowledgements}

The Authors would like to thank Aleksandra Piotrowska, Katarzyna Ratajczak-Wielgomas for technical assistance and Jedrzej Grzegrzolka for support and help in statistical analysis. This research was funded by the Wroclaw Medical University (Project number ST.SUB.A352.19.030).

\section{References}

1 Dekker E, Tanis PJ, Vleugels JLA, Kasi PM and Wallace MB: Colorectal cancer. Lancet 394(10207): 1467-1480, 2019. PMID: 31631858. DOI: 10.1016/S0140-6736(19)32319-0

2 Ferlay J, Colombet M, Soerjomataram I, Dyba T, Randi G, Bettio M, Gavin A, Visser O and Bray F: Cancer incidence and mortality patterns in Europe: Estimates for 40 countries and 25 major cancers in 2018. Eur J Cancer 103: 356-387, 2018. PMID: 30100160. DOI: 10.1016/j.ejca.2018.07.005

3 Siegel RL, Miller KD, Fedewa SA, Ahnen DJ, Meester RGS, Barzi A and Jemal A: Colorectal cancer statistics, 2017. CA Cancer J Clin 67(3): 177-193, 2017. PMID: 28248415. DOI: $10.3322 /$ caac. 21395

4 Wojciechowska U: Zachorowania i zgony na nowotwory złośliwe w Polsce. Krajowy Rejestr Nowotworów. Raport. Available at: http://onkologia.org.pl/wp-content/uploads/ Nowotwory_2018.pdf [Last accessed on October 7, 2021]

5 Guffey CR, Fan D, Singh UP and Murphy EA: Linking obesity to colorectal cancer: recent insights into plausible biological mechanisms. Curr Opin Clin Nutr Metab Care 16(5): 595-600, 2013. PMID: 23743611. DOI: 10.1097/MCO.0b013e328362d10b

6 Mayor PC, Eng KH, Singel KL, Abrams SI, Odunsi K, Moysich KB, Fuleihan R, Garabedian E, Lugar P, Ochs HD, Bonilla FA, Buckley RH, Sullivan KE, Ballas ZK, Cunningham-Rundles $\mathrm{C}$ and Segal $\mathrm{BH}$ : Cancer in primary immunodeficiency diseases: Cancer incidence in the United States Immune Deficiency Network Registry. J Allergy Clin Immunol 141(3): 1028-1035, 2018. PMID: 28606585. DOI: 10.1016/j.jaci.2017.05.024

7 Tabung FK, Liu L, Wang W, Fung TT, Wu K, Smith-Warner SA, Cao Y, Hu FB, Ogino S, Fuchs CS and Giovannucci EL: Association of dietary inflammatory potential with colorectal cancer risk in men and women. JAMA Oncol 4(3): 366-373, 2018. PMID: 29346484. DOI: 10.1001/jamaoncol.2017.4844

8 Dagenais M, Dupaul-Chicoine J, Champagne C, Skeldon A, Morizot A and Saleh M: A critical role for cellular inhibitor of protein 2 (cIAP2) in colitis-associated colorectal cancer and intestinal homeostasis mediated by the inflammasome and survival pathways. Mucosal Immunol 9(1): 146-158, 2016. PMID: 26037070. DOI: 10.1038/mi.2015.46

9 Boström P, Wu J, Jedrychowski MP, Korde A, Ye L, Lo JC, Rasbach KA, Boström EA, Choi JH, Long JZ, Kajimura S, Zingaretti MC, Vind BF, Tu H, Cinti S, Højlund K, Gygi SP and Spiegelman BM: A PGC1- $\alpha$-dependent myokine that drives brown-fat-like development of white fat and thermogenesis. Nature 481(7382): 463-468, 2012. PMID: 22237023. DOI: 10.1038 /nature 10777

10 Panati K, Suneetha Y and Narala VR: Irisin/FNDC5-An updated review. Eur Rev Med Pharmacol Sci 20(4): 689-697, 2016. PMID: 26957272.

11 Gaggini M, Cabiati M, Del Turco S, Navarra T, De Simone P, Filipponi F, Del Ry S, Gastaldelli A and Basta G: Increased FNDC5/Irisin expression in human hepatocellular carcinoma. Peptides 88: 62-66, 2017. PMID: 28012856. DOI: 10.1016/ j.peptides.2016.12.014

12 Moon HS and Mantzoros CS: Regulation of cell proliferation and malignant potential by irisin in endometrial, colon, thyroid and esophageal cancer cell lines. Metabolism 63(2): 188-193, 2014. PMID: 24268368. DOI: 10.1016/j.metabol.2013.10.005

13 Shi G, Tang N, Qiu J, Zhang D, Huang F, Cheng Y, Ding K, Li $\mathrm{W}$, Zhang $\mathrm{P}$ and Tan $\mathrm{X}$ : Irisin stimulates cell proliferation and invasion by targeting the PI3K/AKT pathway in human hepatocellular carcinoma. Biochem Biophys Res Commun 493(1): 585-591, 2017. PMID: 28867187. DOI: 10.1016/j.bbrc. 2017.08.148

14 Liu J, Song N, Huang Y and Chen Y: Irisin inhibits pancreatic cancer cell growth via the AMPK-mTOR pathway. Sci Rep 8(1): 15247, 2018. PMID: 30323244. DOI: 10.1038/s41598-01833229-w

15 Zhang D, Zhang P, Li L, Tang N, Huang F, Kong X, Tan X and Shi G: Irisin functions to inhibit malignant growth of human pancreatic cancer cells via downregulation of the PI3K/AKT signaling pathway. Onco Targets Ther 12: 7243-7249, 2019. PMID: 31564907. DOI: 10.2147/OTT.S214260

16 Nowinska K, Jablonska K, Pawelczyk K, Piotrowska A, Partynska A, Gomulkiewicz A, Ciesielska U, Katnik E, Grzegrzolka J, Glatzel-Plucinska N, Ratajczak-Wielgomas K, Podhorska-Okolow $\mathrm{M}$ and Dziegiel P: Expression of Irisin/FNDC5 in cancer cells and stromal fibroblasts of nonsmall cell lung cancer. Cancers (Basel) 11(10): 1538, 2019. PMID: 31614634. DOI: 10.3390/cancers 11101538

17 Nowinska K, Ciesielska U, Piotrowska A, Jablonska K, Partynska A, Paprocka M, Zatonski T, Podhorska-Okolow M and Dziegiel P: MCM5 expression is associated with the grade of malignancy and Ki-67 antigen in LSCC. Anticancer Res 39(5): 2325-2335, 2019. PMID: 31092424. DOI: 10.21873/anticanres. 13349

18 Nowinska K, Chmielewska M, Piotrowska A, Pula B, Pastuszewski W, Krecicki T, Podhorska-Okołow M, Zabel M and Dziegiel P: Correlation between levels of expression of minichromosome maintenance proteins, Ki-67 proliferation antigen and metallothionein I/II in laryngeal squamous cell 
cancer. Int J Oncol 48(2): 635-645, 2016. PMID: 26648405 . DOI: $10.3892 /$ ijo.2015.3273

19 Cao Q, Chen X, Wu X, Liao R, Huang P, Tan Y, Wang L, Ren G, Huang J and Dong C: Inhibition of UGT8 suppresses basallike breast cancer progression by attenuating sulfatide- $\alpha \mathrm{V} \beta 5$ axis. J Exp Med 215(6): 1679-1692, 2018. PMID: 29728441. DOI: $10.1084 /$ jem. 20172048

20 Kim H, Wrann CD, Jedrychowski M, Vidoni S, Kitase Y, Nagano K, Zhou C, Chou J, Parkman VA, Novick SJ, Strutzenberg TS, Pascal BD, Le PT, Brooks DJ, Roche AM, Gerber KK, Mattheis L, Chen W, Tu H, Bouxsein ML, Griffin PR, Baron R, Rosen CJ, Bonewald LF and Spiegelman BM: Irisin mediates effects on bone and fat via $\alpha \mathrm{V}$ integrin receptors Cell 175(7): 1756-1768.e17, 2018. PMID: 30550785. DOI: 10.1016/j.cell.2018.10.025

21 O'Sullivan B, Brierley J, Byrd D, Bosman F, Kehoe S, Kossary C, Piñeros M, Van Eycken E, Weir HK and Gospodarowicz M: The TNM classification of malignant tumours-towards common understanding and reasonable expectations. Lancet Oncol 18(7): 849-851, 2017. PMID: 28677562. DOI: $10.1016 / \mathrm{S} 1470$ 2045(17)30438-2

22 Remmele W and Stegner HE: [Recommendation for uniform definition of an immunoreactive score (IRS) for immunohistochemical estrogen receptor detection (ER-ICA) in breast cancer tissue]. Pathologe 8(3): 138-140, 1987. PMID: 3303008 .

23 Laemmli UK: Cleavage of structural proteins during the assembly of the head of bacteriophage T4. Nature 227(5259): 680-685, 1970. PMID: 5432063. DOI: 10.1038/227680a0

24 Coffey DS, Getzenberg RH and DeWeese TL: Hyperthermic biology and cancer therapies: a hypothesis for the "Lance Armstrong effect". JAMA 296(4): 445-448, 2006. PMID: 16868303. DOI: $10.1001 /$ jama.296.4.445

25 Aydin S: Is irisin a decisive protein in cancer cachexia and death of cancer cells? Eur Rev Med Pharmacol Sci 20(18): 3727-3729, 2016. PMID: 27735050.

26 Aydin S, Kuloglu T, Ozercan MR, Albayrak S, Aydin S, Bakal U, Yilmaz M, Kalayci M, Yardim M, Sarac M, Kazez A, Kocdor H, Kanat B, Ozercan İH, Gonen M, Bilgen M and Balgetir F: Irisin immunohistochemistry in gastrointestinal system cancers Biotech Histochem 91(4): 242-250, 2016. PMID: 26963139. DOI: $10.3109 / 10520295.2015 .1136988$
27 Wu J, Boström P, Sparks LM, Ye L, Choi JH, Giang AH, Khandekar M, Virtanen KA, Nuutila P, Schaart G, Huang K, Tu $H$, van Marken Lichtenbelt WD, Hoeks J, Enerbäck S, Schrauwen P and Spiegelman BM: Beige adipocytes are a distinct type of thermogenic fat cell in mouse and human. Cell 150(2): 366-376, 2012. PMID: 22796012. DOI: 10.1016/j.cell. 2012.05.016

28 Zhu MY, Milligan N, Keating S, Windrim R, Keunen J, Thakur V, Ohman A, Portnoy S, Sled JG, Kelly E, Yoo SJ, GrossWortmann L, Jaeggi E, Macgowan CK, Kingdom JC and Seed M: The hemodynamics of late-onset intrauterine growth restriction by MRI. Am J Obstet Gynecol 214(3): 367.e1367.e17, 2016. PMID: 26475425. DOI: 10.1016/j.ajog. 2015.10.004

29 Zhu H, Liu M, Zhang N, Pan H, Lin G, Li N, Wang L, Yang H, Yan K and Gong F: Serum and adipose tissue mRNA levels of ATF3 and FNDC5/Irisin in colorectal cancer patients with or without obesity. Front Physiol 9: 1125, 2018. PMID: 30246803. DOI: $10.3389 /$ fphys.2018.01125

30 Us Altay D, Keha EE, Ozer Yaman S, Ince I, Alver A, Erdogan B, Canpolat S, Cobanoglu U and Mentese A: Investigation of the expression of irisin and some cachectic factors in mice with experimentally induced gastric cancer. QJM 109(12): 785-790, 2016. PMID: 27256459. DOI: 10.1093/qjmed/hcw074

31 Argilés JM, Busquets S, Stemmler B and López-Soriano FJ: Cancer cachexia: understanding the molecular basis. Nat Rev Cancer 14(11): 754-762, 2014. PMID: 25291291. DOI: 10.1038/ nrc3829 